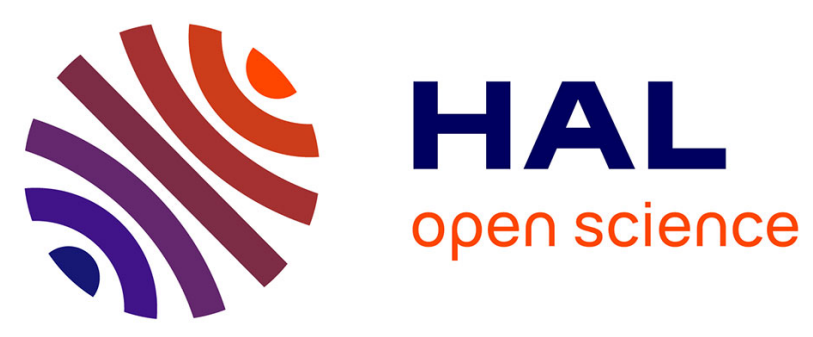

\title{
Wireless Sensors for the Incident Pressure Measurement in Air Blast
}

Jérémie Fourmann, Anthony Coustou, Hervé Aubert, Patrick Pons, Jerôme Luc, A. Lefrancois, Maylis Lavayssière, A Osmont

\section{> To cite this version:}

Jérémie Fourmann, Anthony Coustou, Hervé Aubert, Patrick Pons, Jerôme Luc, et al.. Wireless Sensors for the Incident Pressure Measurement in Air Blast. European Microwave Week (EuMW), Oct 2016, London, United Kingdom. hal-01396861

\section{HAL Id: hal-01396861 https://hal.science/hal-01396861}

Submitted on 15 Nov 2016

HAL is a multi-disciplinary open access archive for the deposit and dissemination of scientific research documents, whether they are published or not. The documents may come from teaching and research institutions in France or abroad, or from public or private research centers.
L'archive ouverte pluridisciplinaire HAL, est destinée au dépôt et à la diffusion de documents scientifiques de niveau recherche, publiés ou non, émanant des établissements d'enseignement et de recherche français ou étrangers, des laboratoires publics ou privés. 


\title{
Wireless Sensors for the Incident Pressure Measurement in Air Blast
}

\author{
J. Fourmann ${ }^{1,2,3}$, A. Coustou ${ }^{1,2}$, H. Aubert ${ }^{1,2}$, P. Pons ${ }^{1,2}$, J. Luc $^{3}$, A. Lefrançois ${ }^{3}$, M.Lavayssière $^{3}$, A.Osmont ${ }^{3}$ \\ ${ }^{1}$ CNRS, LAAS, 7 Avenue du colonel Roche, F-31400 Toulouse, France \\ ${ }^{2}$ Université de Toulouse, LAAS-CNRS, F-31400 Toulouse, France \\ ${ }^{3}$ CEA, DAM, GRAMAT, BP80200, F-46500 Gramat, France
}

\begin{abstract}
This paper addresses the measurement of incident pressure in air blast experiment using wireless pressure sensors. The analysis of the proposed wireless system is presented and measurement results obtained during an air blast event are reported. The proposed approach offers a very attractive solution in terms of cost, size and power consumption for transmitting and analyzing sensor data in harsh environment.
\end{abstract}

Keywords-wireless sensors, pressure measurement, air blast experiment.

\section{INTRODUCTION}

Defense and civil applications have a real need for high bandwidth sensors for pressure measurements. Especially during an explosion, a rapid amount of energy is released and generates a pressure wave with decreasing amplitudes versus distance. The shockwave moves supersonically with discontinuities in pressure, density, particle velocity and temperature across the wave-front. The Figure 1 shows the fireball (red circle) and the shock wave (blue circle) during an air blast experiment. When the shock wave is incident the pressure rises on a 100 nanoseconds range to the socalled peak static overpressure. Then it decays back to the ambient pressure within a 500 microseconds range. Moreover extreme conditions are involved during the measurement. Temperature range is over 1000 degrees Celsius with intense light, reflected shock wave, vibrations, ionized gazes which may impact the measurement setup functionality. Structure vulnerability and high explosive developments need accurate experimental data to compare the peak static overpressure, the maximum positive impulse, the time arrival and the duration of the positive phase of the blast wave with advanced models and hydrocode numerical simulations [1].

Recently many efforts have been devoted for recording the very fast transient pressure occurring during an air blast experiment [2]. Usually pressure sensors networks use several long cables to connect pressure sensors to the acquisition unit. We propose here an alternative approach which consists of using wireless sensors instead of wired sensors to measure the incident pressure in such harsh environment in terms of temperature, pressure and mechanical vibrations.

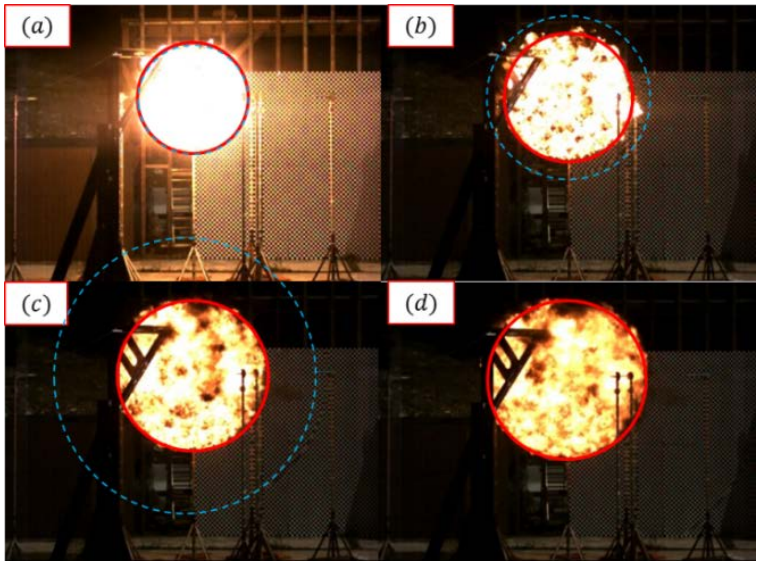

Fig. 1. Fireball during the air blast at time (a) $t=0.5 \mathrm{~ms}$; (b) $t=0.9 \mathrm{~ms}$; (c) $t=2.6 \mathrm{~ms}$ and (d) $t=5 \mathrm{~ms}$ after the explosion $(t=0)$.

\section{WIRELESS SENSORS SOLUTION}

\section{A. Wireless system overview}

The wireless setup proposed here is composed of transmitter and receiver units operating at $6 \mathrm{GHz}$ with $100 \mathrm{MHz}$ bandwidth (see Figure 2). During the experiment, the transmitter unit converts the output voltage of the piezoelectric sensor (based on a PVDF film) with a sensitivity $S_{c}=120 \mathrm{mV} / \mathrm{bar}$ into a frequency shift by using a Voltage Controlled Oscillator (VCO). The resulting frequency modulated (FM) signal is wirelessly transmitted to the receiver unit through the fireball. The received FM signal is then filtered and amplified by the receiver unit. The Intermediate Frequency (IF) is obtained from the mixing of the received modulated signal with the stable sinusoidal signal generated by the $6 \mathrm{GHz}$ Local Oscillator (LO).

The frequency demodulation process applied to the IF signal is finally performed numerically by using the Short-Time Fourier Transform (STFT). The Figure 3 shows the developed receiver unit based on commercial off-the-shelf components. 


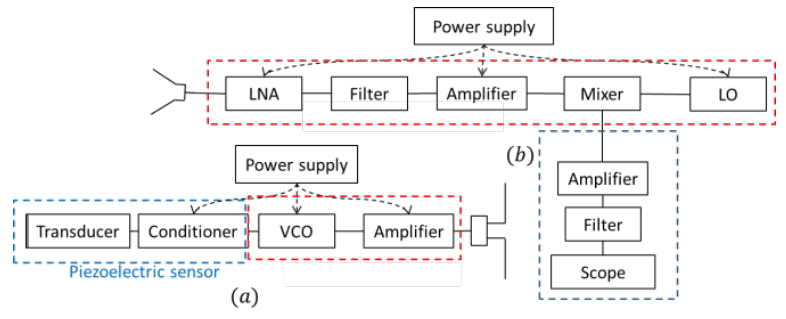

Fig. 2. Block diagram of the wireless sensor system: (a) transmitter unit and (b) receiver unit

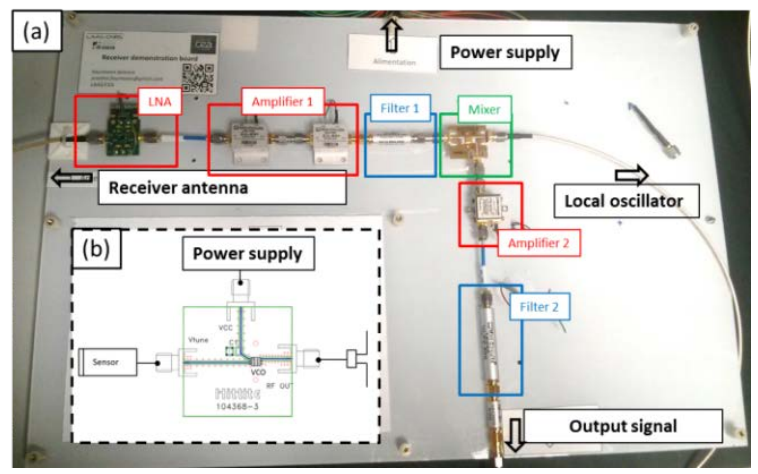

Fig. 3. Developed (a) receiver unit and (b) transmitter unit.

\section{B. System bandwith performance}

The VCO is the key component of the transmitter unit. With only one component, the transmitter allows converting the variation $\Delta V_{m}$ of the sensor output voltage $V_{m}$ in a frequency shift $\Delta f \cong K_{0} \Delta V_{m}$, where $K_{0}$ is called the sensitivity coefficient of the VCO. In the receiver unit, the FM demodulator converts this frequency shift into a voltage variation $\Delta V$ given by $\Delta V \cong K_{D} \Delta f$, where $K_{D}$ is called the sensitivity of the demodulator. In our case $K_{0} K_{D} \cong 1$ and we have $\Delta V \cong$ $\Delta V_{m}$. Consequently, the measurement of $\Delta V$ at the output of the demodulator allows the direct acquisition of the voltage variation $\Delta V_{m}$ at the sensor output. In order to measure without distortion the sensor voltage $V_{m}$ from the receiver voltage $V$, the VCO component must have an input bandwidth larger than the sensor bandwidth. The equivalent electrical circuit of the VCO is given in the Figure 4. The 3dB-bandwidth of the chosen VCO is $137 \mathrm{MHz}$ which is large enough in our application. The bandwidth of the overall transmitter unit will be mainly limited by the dynamic response of the sensor transduction.

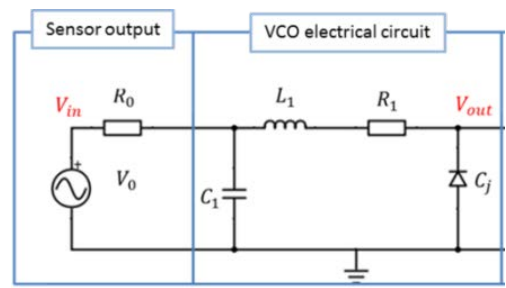

Fig. 4. The VCO electrical model with $\mathrm{L}_{1}=7.5 \mathrm{nH}, \mathrm{R}_{1}=150 \Omega$, $\mathrm{C}_{1}=2.4 \mathrm{pF}$ and $\mathrm{C}_{\mathrm{j}}=3.6 \mathrm{pF}\left(\mathrm{R}_{0}=50 \Omega\right)$.

\section{Measurement uncertainty}

This section reports the evaluation of the measurement uncertainty of the voltage measured at the output of the FM demodulator $V(t)$. The block diagram of the wireless system is shown in Figure 5.

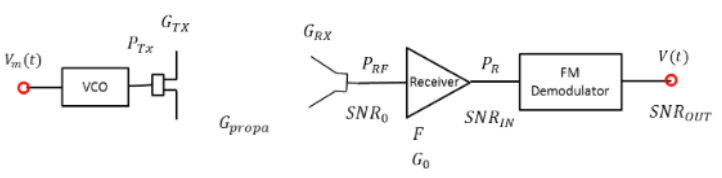

Fig. 5. Block diagram of the RF system used for wirelessly transmitting the sensor output voltage $V_{m}$ to the receiver unit

In Figure 5, $G_{\text {propa }}$ denotes the propagation loss (the effect of the reflection on the ground is taken into account). In our experiment, the distance between the $\mathrm{T}_{\mathrm{X}}$ - and $\mathrm{R}_{\mathrm{X}}$-antennas is 22 meters. The gains of these antennas are $G_{T X}$ and $G_{R X}$ respectively, and the received power $P_{R F}$ is given by $P_{R F}=$ $P_{T X} G_{T X} G_{R X} G_{\text {propa }}$, where $P_{T X}$ denotes the transmitted power. Let the harmonic voltage $V_{m}(t)$ be applied at the VCO input, that is $V_{m}(t)=C \cos \left(2 \pi f_{m} t\right)$, where $C$ and $f_{m}$ denote respectively the amplitude and the frequency of $V_{m}(t)$. The signal-to-noise ratio $S N R_{\text {OUT }}$ at the output of the demodulator is then given by [3]:

$$
S N R_{\text {OUT }} \cong \frac{3}{2} m_{0}^{2} \frac{B}{f_{m}} S N R_{I N}, \text { for } S N R_{I N}>10 \mathrm{~dB}
$$

where $S N R_{I N}$ denotes the signal-to-noise ratio at the demodulator input, $m_{0}$ the FM modulation rate and $B$ the bandwidth of the modulated RF signal. The relative measurement uncertainty $\Delta V / V$ on the voltage at the demodulator output is then given by:

$$
\frac{\Delta V}{V}=\frac{1}{\sqrt{\frac{3}{2} \frac{m_{0}^{2}}{f_{m}} \frac{P_{R F}}{F N_{0}}}}
$$

where $F$ and $N_{0}$ denote respectively the noise factor of the receiver unit and the noise spectral density. From the parameters of our system (see Table 1), we obtained $\Delta V / V=2.5 \%$. However, the thermal noise of the electronic devices is not the unique source of noise (or uncertainty) generated in our system. A biased value $\Delta K_{0}$ on the VCO sensitivity coefficient $K_{0}$ causes a systematic bias error $\Delta V_{0}$ on the demodulator output voltage $V$ given as follows:

$$
\frac{\Delta V_{0}}{V}=\frac{\Delta K_{0}}{K_{0}}
$$

where $\Delta K_{0} / K_{0}$ characterizes the uncertainty on the value of VCO sensitivity coefficient. If this uncertainty 
is not considered in the system design, the condition $K_{0} K_{D} \cong 1$ (see Section II.B) may be not valid and consequently, the voltage $V$ at the output of the FM demodulator may not be accurately released from the voltage $V_{m}$ at the sensor output.

Table 1: Wireless System key parameters

\begin{tabular}{|c|c|c|}
\hline & Symbol & Value \\
\hline $\begin{array}{c}\text { VCO sensitivity coeff. } \\
\text { Coeff. }\end{array}$ & $K_{0}$ & $200 \mathrm{MHz} / \mathrm{V}$ \\
\hline $\begin{array}{c}\text { Modulation rate } \\
\text { Modulation frequency }\end{array}$ & $m_{0}$ & $25 \mathrm{MHz} / \mathrm{V}^{2}$ \\
\hline $\begin{array}{c}\text { RF power at the VCO } \\
\text { output }\end{array}$ & $P_{T X}$ & $15 \mathrm{MHz}$ \\
\hline $\begin{array}{c}\text { Modulated RF signal } \\
\text { bandwith }\end{array}$ & $B$ & $500 \mathrm{MHz}$ \\
\hline $\begin{array}{c}\text { Noise spectral density } \\
\text { Power gain of the } \\
\text { receiver amplifier }\end{array}$ & $N_{0}$ & $-170 \mathrm{dBm} / \mathrm{Hz}$ \\
\hline $\begin{array}{c}\text { Noise factor of the } \\
\text { receiver unit }\end{array}$ & $F$ & $45 \mathrm{~dB}$ \\
\hline Propagation loss & $G_{p r o p a}$ & $-75 \mathrm{~dB}$ \\
\hline Tx-antenna gain & $G_{T X}$ & $2.5 \mathrm{~dB}$ \\
\hline Rx-antenna gain & $G_{R X}$ & $15 \mathrm{~dB}$ \\
\hline
\end{tabular}

The value of the VCO sensitivity coefficient $K_{0}$ is given in the datasheet of this component. The temperature of the VCO and the values of the impedances connected at its input and output ports may affect the nominal value of $K_{0}$. Moreover, the secondorder approximation for the frequency at the VCO output requires to consider the VCO sensitivity coefficient $K_{0}=\partial f / \partial V_{m}$ and the second-order coefficient $K_{1}=\partial^{2} f / \partial V_{m}{ }^{2}$. The coefficient $K_{1}$ allows taking into account the non-linear tuning sensitivity of the VCO and it introduces a systematic error $\Delta V_{1}$ on the demodulator output voltage given as follows:

$$
\frac{\Delta V_{1}}{V} \leq \frac{K_{1}}{2 K_{0}} V_{\max }
$$

where $V_{\max }$ is the maximal VCO input voltage. Here $V_{\text {max }}=280 \mathrm{mV}$ and consequently the voltage uncertainty derived from Eq.(4) is found to be $0.5 \%$. Due to the low voltage magnitude of the VCO input signal, this bias is small. The total relative measurement uncertainty $\Delta V / V$ on the voltage at the demodulator output and for a temperature compensated sensor is 3\% with a coverage factor $k=$ 1 . In order to reduce this uncertainty, the biasing sources of the VCO component should be compensated through a calibration process. As a consequence, the measurement uncertainty would mainly originate in the thermal noise of the system electronic devices $(\Delta V / V=2.5 \%$ with $k=1)$. We will show in the next section that the proposed system, as it stands, allows wirelessly measuring the peak static overpressure reached in a rise time of few microseconds (transient phase) during an air blast experiment.

\section{MeAsurement Results and Discussion}

The wireless air blast experiment is illustrated in the Figure 6(a). The transmitter unit (including the piezoelectric sensor) is placed inside the fireball during the blast event for sensing the pressure signal variation very close to the explosive. The sensing device is located at 1.6 meter of the $1 \mathrm{~kg}$ TNT high explosive sphere. The transmitter unit was not calibrated $\left(K_{0} K_{D} \neq 1\right)$ during this experiment in order to observe the impact of various biasing sources on the measurement accuracy. Both the wireless link and a classical wired link are used between the transmitter and receiver units to simultaneously read the pressure variations measured by the sensor. These two links allow comparing the measurement results obtained from the traditional wired system (reference signal) and ones provided by the proposed wireless solution. The receiver unit is located at 22 meters of the explosive in front of a bunker to offer protection during the explosion and blast event. An ultra-fast camera is also installed to capture the fireball expansion. The figure 6(b) shows the sensor installed on the instrumentation mast. During the measurement process, the internal temperature of the sensor is found to be lower than the highest admissible temperature of the transmitter, verified by acoustic-electric computations inside the gauge. The pressure signal is transmitted in real time when the shock wave reaches the pressure sensing device. The spectrogram of the IF signal derived numerically from the use of a ShortTime Fourier Transform (STFT) is shown in the Figure 7(a). The demodulation process consists of finding the set of maxima in this spectrogram. In Figure 7(b), the resulting signal is compared to the signal obtained from the wired link. The difference between these two signals does not exceed 0.300 bar. During the transient phase the wireless measured of the peak static overpressure is $2.300 \pm 0.035$ bar (with $k=1$ ) with a rise time around $1 \mu \mathrm{s}$. This uncertainty is deducted from section II analysis. The measured positive phase duration is $100 \mu \mathrm{s}$. A discrepancy on the impulse has been observed with the reference quartz sensor due to the applied conditioner with a too high low pass frequency. 


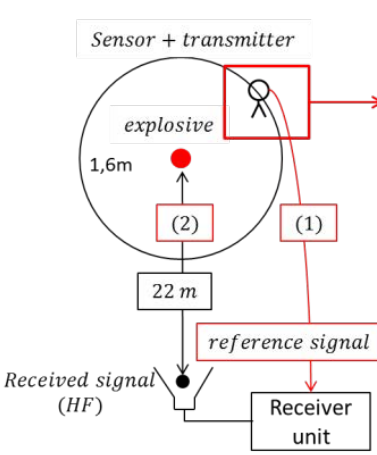

(a)

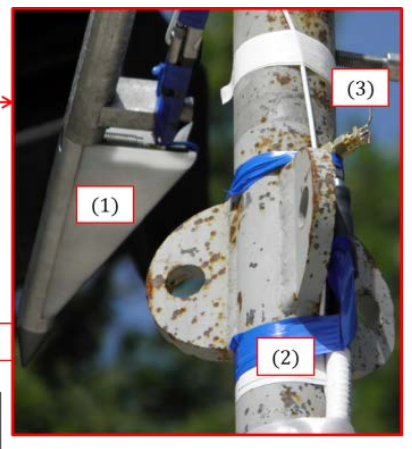

(b)
Fig. 6. (a) Overview of the air blast experimental setup [path (1): wired link; path (2): wireless link] and (b) zoom at the sensor location $\{(1)$ the probe with the PVDF pressure sensor, (2) the sensor support, (3) the Tx-antenna (halfwavelength dipole)\}

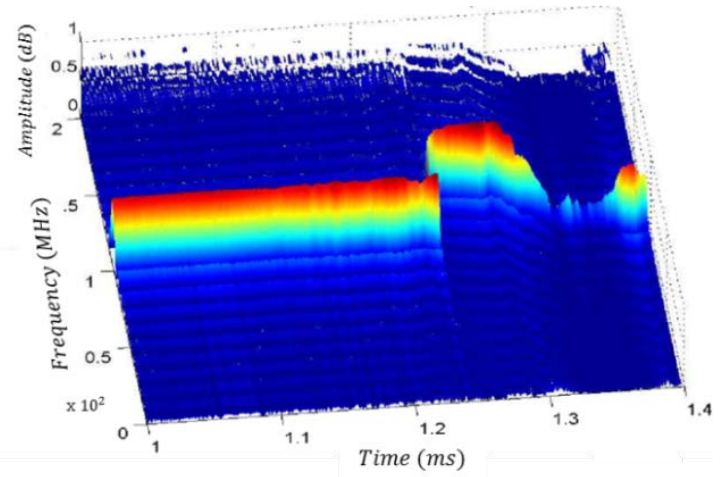

(a)

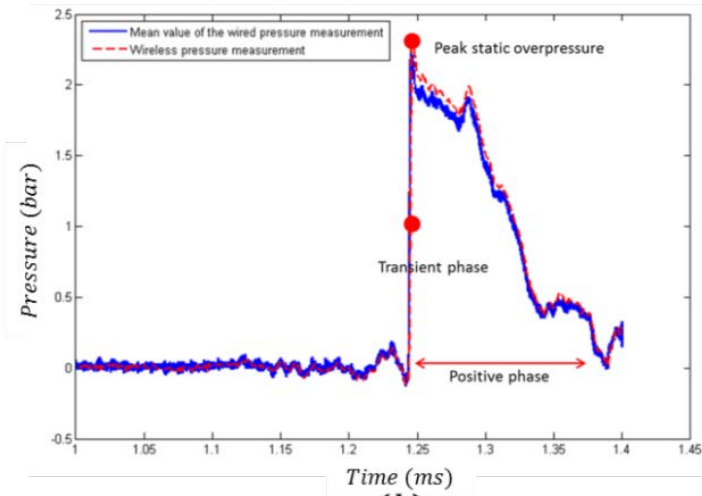

(b)

Fig. 7.(a) Short-Time Fourier Transform of the IF signal; (b) voltage at the output of the demodulator using the proposed wireless system (red curve) and voltage obtained from the traditional wired link using RG58 coaxial cable (blue curve).

\section{CONCLUSION}

A complete FM-based wireless system solution for air blast pressure measurement is proposed and experimentally validated in this paper. The air blast experiment has demonstrated the system robustness for a wireless sensor placed inside the fireball generated by an explosion. The proposed wireless transmission could be an interesting alternative to wired transmission techniques for air blast measurement and the architecture of the developed system is fully appropriate for sensors network purposes

Future works are focusing on the development of a complete and integrated sensors network optimized for air blast environment and on the compensation of the impact of the temperature on the VCO sensitivity.

\section{ACKNOWLEDGEMENTS}

The authors thank Fabrice Mathieu for the help during the development of the high bandwidth sensor conditioner and the region Languedoc Roussillon Midi-Pyrenees for contributing to the financial support of this work.

\section{REFERENCES}

[1] Silver, P. L., "Evaluation of Air Blast Measurement Techniques”, 75th Shock and Vibration Proceedings, Virginia Beach, VA, October 17 - 22, 2004.

[2] Walter, Patrick L., "Air-blast and the Science of Dynamic Pressure Measurements," Sound and Vibration, pp. 10-16, December 2004.

[3] Michael Fitz, Fundamentals of Communications Systems, McGraw-Hill Education, 2007, pp 51. 